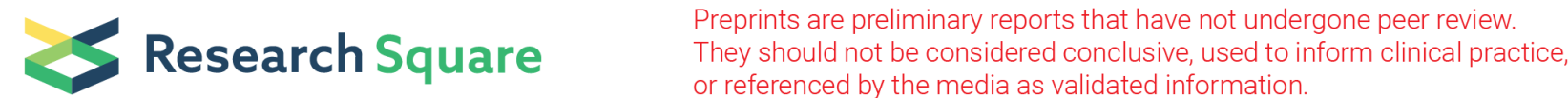

\section{Synchronous/Metachronous Endometrial and Colorectal \\ Malignancies in Taiwanese Women: A Population-Based Nationwide Study}

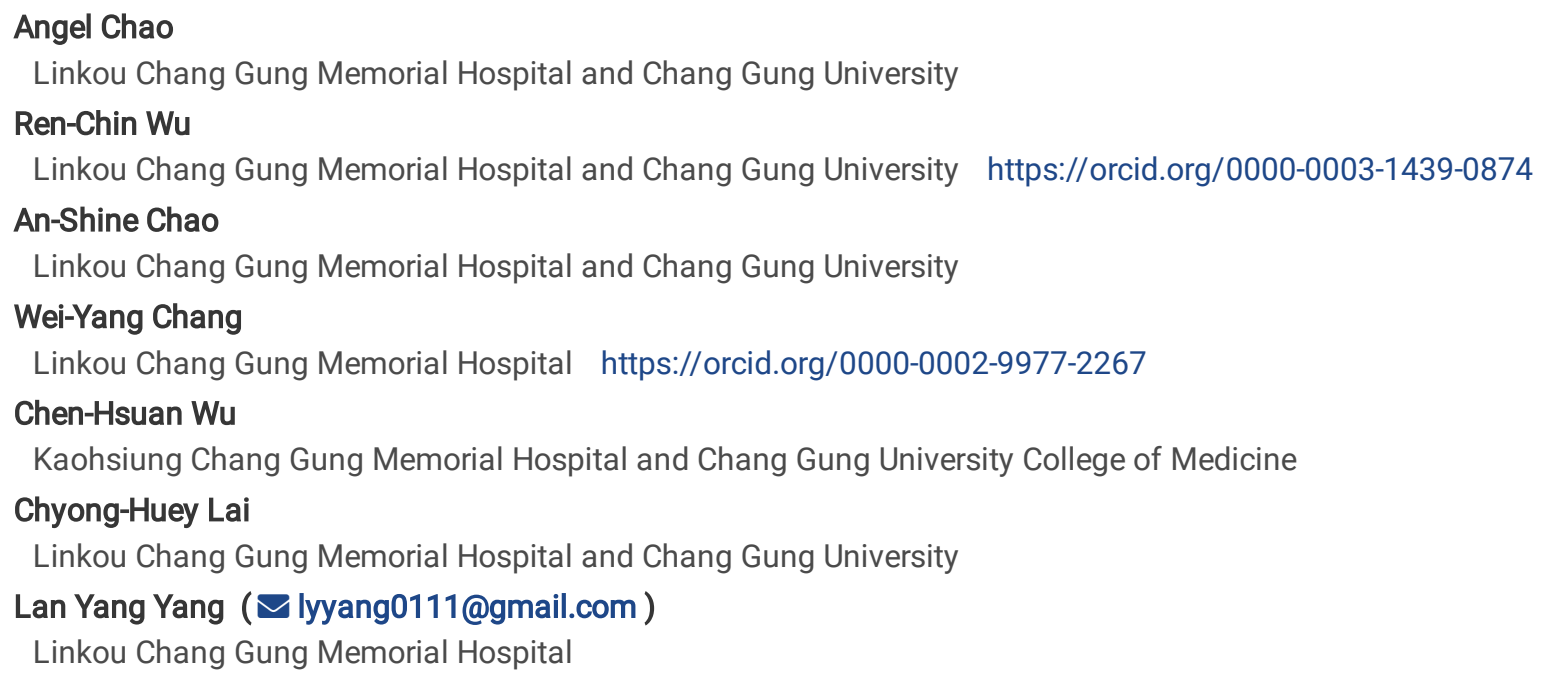

\section{Research Article}

Keywords: Endometrial cancer, Colorectal cancer, Metachronous tumors, Synchronous tumors, Taiwan

Posted Date: July 20th, 2021

DOI: https://doi.org/10.21203/rs.3.rs-644095/v1

License: (c) (1) This work is licensed under a Creative Commons Attribution 4.0 International License. Read Full License

Version of Record: A version of this preprint was published at Archives of Gynecology and Obstetrics on January 10th, 2022. See the published version at https://doi.org/10.1007/s00404-021-06296-0. 


\section{Abstract \\ Introduction}

Endometrial cancer (EC) and colorectal cancer (CRC) may share a common genetic background. In a subset of patients, the two malignancies can coexist either at the time of diagnosis (synchronous) or develop consequently (metachronous). The purpose of this nationwide, population-based study was to investigate the occurrence and clinical outcomes of synchronous/metachronous EC/CRC in Taiwanese women.

\section{Materials and methods}

Data for women diagnosed with EC and/or CRC between 2007 and 2015 were retrospectively retrieved from the nationwide Taiwan Cancer Registry. Mortality data were obtained from the National Death Registry. Women with synchronous/metachronous EC/CRC versus EC or CRC were compared in terms of clinical characteristics and outcomes.

\section{Results}

Of the 62,764 Taiwanese women diagnosed with EC and/or CRC during the study period, 167 (0.3\%) had synchronous/metachronous EC/CRC. Among them, 72 cases (43.1\%) presented with EC followed by CRC, 66 (39.5\%) with CRC followed by EC, and 29 (17.4\%) with synchronous EC/CRC. Kaplan-Meier estimates for time-to-event data revealed that the 2-year risk rates of developing a metachronous tumor of interest (CRC or EC) in women diagnosed with an initial EC and CRC were $39.6 \%$ and $42.1 \%$, respectively. The 5-year overall survival rates of women with metachronous EC/CRC who had an initial diagnosis of EC, CRC, and synchronous EC/CRC were $73.9 \%, 70.9 \%$, and $37.0 \%$, respectively.

\section{Conclusions}

EC is the most common first tumor in Taiwanese women with metachronous EC/CRC. The 2-year risk rates of developing a metachronous tumor of interest (CRC or EC) in women diagnosed with an initial EC and CRC are not negligible. Surveillance for CRC is recommended for all women diagnosed with EC. The clinical outcomes of synchronous EC/CRC are markedly less favorable.

\section{Introduction}

Epidemiological data have shown that the incidence rates of endometrial cancer (EC) - which is the sixth most common gynecologic malignancy worldwide - have been rising in countries characterized by rapid socioeconomic transitions [1, 2]. On analyzing the burden of EC in Taiwanese women, the incidence has been reported to increase from 11.96 cases per 100,000 person in 2012 to 15.11 cases per 100,000 person in 2018 [3, 4]. The most common histological type of EC is endometrioid carcinoma - which comprises approximately 85\% of all cases, with the remaining types being serous carcinomas (3-10\%) and clear cell carcinomas ( $<5 \%$ [5]. A molecular classification of EC has also been proposed [6].

Recent years have witnessed a growing interest in the biological links between EC and colorectal cancer (CRC) [7, 8]. Specifically, evidence has emerged that the two malignancies may share a common genetic background - which appears mainly related to germline mutations in the mismatch repair (MMR) genes [7]. In a subset of patients, the two malignancies can also coexist either at the time of diagnosis (synchronous) or develop consequently (metachronous). The coexistence of EC and CRC is also typical of the Lynch syndrome (LS), which is one of the most common autosomal dominant cancer susceptibility disorder [9-12].

While inherited EC (including malignancies occurring in patients with LS) accounts for only 5\% of all cases [13], no large-cohort studies in the Asian population have specifically investigated the risk of metachronous EC/CRC to inform surveillance guidelines. In addition, the survival figures of women who develop metachronous EC/CRC remain poorly investigated. The purpose of this nationwide, populationbased study was to examine the occurrence and clinical outcomes of metachronous EC/CRC in Taiwanese women, and to assess whether any difference exists compared with those presenting with EC or CRC.

\section{Materials And Methods}




\section{Data source}

The present retrospective study, using data obtained from the nationwide Taiwan Cancer Registry (TCR) database (Health and Welfare Data Science Center, Ministry of Health and Welfare, Taiwan), complied with the principles set forth in the Declaration of Helsinki. The TCR was first established in 1979 and has prospectively recorded information on all patients with malignancies in Taiwan, along with site-specific variables and other clinical parameters related to patient care. As of 2005, the reported completeness of data registration in the TCR ranged between $97 \%$ and $98.4 \%$ [14]. Variables for this study were retrospectively retrieved for all of the Taiwanese women who were diagnosed with EC and/or CRC between January 1, 2007 and December 31, 2015. Once fully anonymized, the dataset was processed under current data protection laws and regulations. Ethics approval was received from the Institutional Review Board of the Chang Gung Medical Foundation (approval number: 201801202B0C502). The requirement for written informed consent was waived due to the study design.

\section{Diagnostic classification and survival analysis}

Eligibility criteria comprised women with a diagnosis of EC and/or CRC who were included in the TCR. Diagnoses in this registry are coded according to the International Classification of Diseases for Oncology, Third Edition (ICD-0-3). Specifically, women were deemed eligible in presence of the following disease codes: C540-C543 and C548-C549 (EC); C180, C182-C189, C199, and C209 (CRC) [15]. EC included the following histological types: endometrioid carcinoma, serous carcinoma, and clear cell carcinoma (histology codes: 8010, 8013, 8020, $8041,8140,8263,8310,8323,8380,8382,8441,8480$, and 8570). Patients with EC were staged using the TNM criteria. The histology codes for colorectal adenocarcinoma were as follows: 8000, 8010, 8020, 8140, 8210, 8246, 8260, 8261, 8262, 8263, 8480, 8481, 8490, and 8570. Once women diagnosed with both EC and CRC were identified, the chronological order of the malignancies was assessed based on the date of diagnosis. Tumors that occurred within three months of the diagnosis of the previous neoplasm were considered as synchronous, whereas those that occurred more than three months apart were considered as metachronous. All-cause mortality data were retrieved from the Taiwanese National Death Registry (NDR) of the Department of Health [16]. Overall survival (OS) was defined as the time interval from the initial-cancer diagnosis to death from any cause, or censored at the last follow-up. Follow-up was terminated on December 31, 2017.

\section{Statistical analysis}

Differences between multiple groups on continuous variables were analyzed using one-way analysis of variance followed by the Tukey's post-hoc multiple comparison test. The chi-square test was used to examine the association of the categorical variables between groups. Cumulative survival curves were plotted with the Kaplan-Meier method and compared with the log-rank test, and post-hoc adjustments were applied for pairwise comparisons. All analyses were performed with SAS, version 9.4 (SAS Institute Inc., Cary, NC, USA). Statistical significance was determined by a two-tailed $p$ value $<0.05$.

\section{Results}

\section{Prevalence and temporal sequence of synchronous/metachronous endometrial and colorectal cancers}

A total of 62,764 Taiwanese women were diagnosed with EC and/or CRC between 2007 and 2015. Of them, 13,887 (22.1\%), 48,710 (77.6\%), and $167(0.3 \%)$ had EC, CRC, and synchronous/metachronous EC/CRC, respectively. In the synchronous/metachronous group, 72 cases (43.1\%) presented with EC followed by CRC, 66 (39.5\%) with CRC followed by EC, and 29 (17.4\%) with synchronous EC/CRC (Fig. 1).

\section{Characteristics of women with synchronous/metachronous endometrial and colorectal cancers}

The characteristics of women diagnosed with EC, CRC, and synchronous/metachronous EC/CRC are shown in Table 1. There were significant intergroup differences in terms of mean age at diagnosis, which was significantly higher in women with $C R C(p<0.001)$. When dividing the metachronous EC/CRC into three groups (initial EC, initial CRC, and synchronous, Table 2), significant differences in age between groups were also observed $(p<0.001)$. Post-hoc pairwise comparisons indicated that the age at diagnosis in synchronous (mean: 61.3 years) was significantly different from EC group (mean: 54.3 years, $p=0.045$ ). Similar to $E C$, early-stage disease was commonly observed in women with synchronous/metachronous EC/CRC. In contrast, early-stage CRC occurred more frequently in women with synchronous/metachronous EC/CRC compared to those diagnosed with CRC (Table 1). On analyzing the histology distribution of EC in patients with synchronous/metachronous EC/CRC or EC, no significant differences were found. 
Table 1

Characteristics of the population-based cohort of 62,764 women in Taiwan between 2007 and 2015

\begin{tabular}{|c|c|c|c|c|c|c|c|}
\hline \multirow{2}{*}{$\begin{array}{l}\text { Variable } \\
\text { Number of cases }\end{array}$} & EC & & \multicolumn{2}{|l|}{ CRC } & \multicolumn{2}{|c|}{$\begin{array}{l}\text { Metachronous } \\
\text { EC/CRC }\end{array}$} & \multirow[t]{2}{*}{$p$ value } \\
\hline & 13,887 & $(22.1)$ & 48,710 & $(77.6)$ & 167 & $(0.3)$ & \\
\hline \multicolumn{8}{|c|}{ Age (years) at first cancer diagnosis } \\
\hline Mean (SD) & 54.3 & $(11.0)$ & 66.2 & $(14.1)$ & 56.8 & $(11.6)$ & $<.001$ \\
\hline$<50(\%)$ & 4249 & $(30.6)$ & 6286 & $(12.9)$ & 45 & $(26.9)$ & $\begin{array}{l}< \\
0.001\end{array}$ \\
\hline$\geq 50(\%)$ & 9638 & $(69.4)$ & 42,424 & $(87.1)$ & 122 & $(73.1)$ & \\
\hline EC histology, count (\%) & & & & & & & 0.298 \\
\hline Endometrioid carcinoma & 13,248 & $(95.4)$ & & & 156 & $(93.4)$ & \\
\hline Serous carcinoma & 627 & $(4.5)$ & & & 11 & $(6.6)$ & \\
\hline Clear cell carcinoma & 12 & $(0.1)$ & & & 0 & $(0)$ & \\
\hline EC stage, count (\%) & 10,955 & & & & 114 & & 0.116 \\
\hline I & 8173 & $(74.6)$ & & & 79 & $(69.3)$ & \\
\hline II & 698 & $(6.4)$ & & & 13 & $(11.4)$ & \\
\hline III & 1440 & $(13.1)$ & & & 13 & (11.4) & \\
\hline IV & 644 & $(5.9)$ & & & 9 & $(7.9)$ & \\
\hline CRC stage, count (\%) & & & 42,163 & & 147 & & 0.002 \\
\hline I & & & 8460 & $(20.1)$ & 35 & $(23.8)$ & \\
\hline II & & & 10,202 & $(24.2)$ & 50 & $(34.0)$ & \\
\hline III & & & 13,482 & $(32.0)$ & 44 & $(29.9)$ & \\
\hline IV & & & 10,019 & $(23.8)$ & 18 & $(12.2)$ & \\
\hline \multicolumn{8}{|c|}{$\begin{array}{l}\text { Temporal sequence of metachronous tumors, } \\
\text { count (\%) }\end{array}$} \\
\hline EC followed by CRC & & & & & 72 & $(43.1)$ & \\
\hline CRC followed by EC & & & & & 66 & (39.5) & \\
\hline Synchronous EC/CRC & & & & & 29 & $(17.4)$ & \\
\hline
\end{tabular}


Table 2

Age of different patient groups

\begin{tabular}{|c|c|c|c|c|c|c|c|c|c|c|c|}
\hline \multirow{2}{*}{ 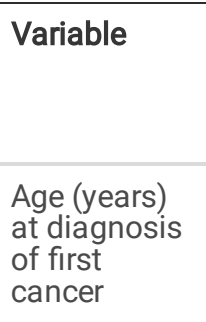 } & EC & & \multicolumn{2}{|l|}{ CRC } & \multicolumn{2}{|c|}{$\begin{array}{l}\text { Initial EC } \\
\text { followed by } \\
\text { CRC }\end{array}$} & \multicolumn{2}{|c|}{$\begin{array}{l}\text { Initial CRC } \\
\text { followed by EC }\end{array}$} & \multicolumn{2}{|c|}{$\begin{array}{l}\text { Synchronous } \\
\text { EC/CRC }\end{array}$} & \multirow[t]{2}{*}{$\begin{array}{l}\mathrm{P} \\
\text { value }\end{array}$} \\
\hline & & & & & & & & & & & \\
\hline Mean (SD) & 54.3 & $(11.0)$ & 66.2 & $(14.1)$ & 56.1 & (11.6) & 55.5 & (10.8) & 61.3 & (12.4) & $\dot{0.001}$ \\
\hline $\begin{array}{l}\text { Median } \\
\text { (range) }\end{array}$ & 54 & $\begin{array}{l}(19- \\
94)\end{array}$ & 67 & $\begin{array}{l}(13- \\
109)\end{array}$ & 56.5 & $\begin{array}{l}(35- \\
87)\end{array}$ & 54.5 & $\begin{array}{l}(27- \\
76)\end{array}$ & 59 & $\begin{array}{l}(38- \\
91)\end{array}$ & \\
\hline $\begin{array}{l}<50 \text {, count } \\
(\%)\end{array}$ & 4249 & $(30.6)$ & 6286 & $(12.9)$ & 23 & $(31.9)$ & 17 & $(25.8)$ & 5 & $(17.2)$ & $\dot{0.001}$ \\
\hline$\underset{(\%)}{\geq 50, \text { count }}$ & 9638 & $(69.4)$ & 42,424 & $(87.1)$ & 49 & $(68.1)$ & 49 & $(74.2)$ & 24 & (82.8) & \\
\hline \multicolumn{12}{|l|}{$\begin{array}{l}\text { Adjusted } \\
\text { pairwise p } \\
\text { value }\end{array}$} \\
\hline EC & & & $<.001$ & & 0.795 & & 0.958 & & 0.045 & & \\
\hline CRC & $\begin{array}{l}<.001 \\
0.00\end{array}$ & & & & $\begin{array}{l}<.001 \\
0.00\end{array}$ & & $\begin{array}{l}<.001 \\
0.00\end{array}$ & & 0.293 & & \\
\hline $\begin{array}{l}\text { Initial EC } \\
\text { followed by } \\
\text { CRC }\end{array}$ & 0.795 & & $<.001$ & & & & 0.999 & & 0.414 & & \\
\hline $\begin{array}{l}\text { Initial CRC } \\
\text { followed by } \\
\text { EC }\end{array}$ & 0.958 & & $\begin{array}{l}< \\
0.001\end{array}$ & & 0.999 & & & & 0.306 & & \\
\hline $\begin{array}{l}\text { Synchronous } \\
\text { EC/CRC }\end{array}$ & 0.045 & & 0.293 & & 0.414 & & 0.306 & & & & \\
\hline
\end{tabular}

\section{Epidemiological trends of endometrial and colorectal cancers}

Throughout the study period (2007-2015), the incidence rates of EC and CRC in Taiwanese women both showed upward trends (Fig. 2). A similar - albeit less striking - pattern was observed for synchronous/metachronous EC/CRC, whose incidence reached 0.28 cases (95\% confidence interval: $0.20-0.39$ ) per 100,000 persons in 2015. The number of women with an initial diagnosis of EC who subsequently developed CRC, as well as of those who were initially diagnosed with CRC who subsequently developed EC, is depicted in Fig. 3. Based on the Kaplan-Meier estimates for time to developing a second metachronous tumor of interest (i.e., CRC or EC), the 2-year risk rates of women initially diagnosed with EC (including synchronous malignancies) and CRC (including synchronous malignancies) were $39.6 \%$ and $42.1 \%$, respectively. The 5 -year risk rates were $11.9 \%$ and $8.4 \%$, respectively. There was no significant difference in time of developing a second metachronous tumor of CRC/EC for women who presented with initial EC versus initial CRC (log-rank, $\mathrm{p}=0.677$ ).

\section{Survival analysis}

The median follow-up time was 1.4 years (range: 0 - 10.8 years). The 5 -year OS rates of women with EC, CRC, and synchronous/metachronous EC/CRC were $81.1 \%, 40.0 \%$, and $66.9 \%$, respectively. The 10 -year OS rates in the three study groups were $72.8 \%, 24.0 \%$, and $43.6 \%$, respectively. Therefore, women with EC had more favorable OS than those with synchronous/metachronous EC/CRC $(p<0.001)$. The poorest survival outcomes were observed for women with CRC $(p<0.001$ versus both EC and synchronous/metachronous EC/CRC; Fig. 4 and Table 3). The 5-year OS rates of women with synchronous/metachronous EC/CRC ( $n=$ 167) who received an initial diagnosis of EC, CRC, and synchronous EC/CRC were $73.9 \%, 70.9 \%$, and $37.0 \%$, respectively (Fig. 5 and Table 3). Collectively, these results indicate that the OS patterns of women with metachronous EC/CRC who had an initial diagnosis of EC and CRC were similar and significantly more favorable compared with that observed in synchronous EC/CRC (adjusted $p$ values $=0.004$ and 0.012, respectively; Table 3). 
Table 3

Survival comparison between different study groups

\begin{tabular}{|lcc|}
\hline Comparison & Log-rank P value & Adjusted P value \\
\hline EC, CRC, and metachronous EC/CRC & $<0.001$ & \\
\hline EC versus CRC & & $<0.001$ \\
\hline EC versus metachronous EC/CRC & $<0.001$ \\
\hline CRC versus metachronous EC/CRC & $<0.001$ \\
\hline Initial EC followed by CRC, initial CRC followed by EC, and synchronous EC/CRC & $<0.001$ \\
\hline Initial EC followed by CRC versus initial CRC followed by EC & \\
\hline Initial EC followed by CRC versus synchronous EC/CRC & 0.965 \\
\hline Initial CRC followed by EC versus synchronous EC/CRC & 0.004 \\
\hline Abbreviations: EC, endometrial cancer; CRC, colorectal cancer & 0.012 \\
\hline
\end{tabular}

\section{Discussion}

The main results of this nationwide population-based study conducted in Taiwan are as follows: 1) metachronous EC/CRC is more commonly characterized by the onset of EC as the first tumor; 2) women with synchronous EC/CRC tend to be older than those with EC; 3 ) early-stage CRC was observed more frequently in women with synchronous/metachronous EC/CRC compared with those showing CRC; 4) the 2-year risk rates of developing a second metachronous tumor of interest (i.e., EC or CRC) in women initially diagnosed with EC (including synchronous malignancies) and CRC (including synchronous malignancies) were 39.6\% and 42.1\%, respectively, 5) the 5-year 0S rates of women with $\mathrm{EC}, \mathrm{CRC}$, and synchronous/metachronous $\mathrm{EC} / \mathrm{CRC}$ were $81.1 \%, 40.0 \%$, and $66.9 \%$, respectively, and 6 ) women with synchronous EC/CRC had the less favorable 5-year OS rate (37.0\%).

In a previous study conducted in Taiwanese women with EC, the cumulative incidence of a second primary cancer was significantly higher in those aged $\geq 50$ years than in younger patients [17]. Notably, the age at diagnosis of first EC for patients who subsequently developed a second primary CRC was 54.7 years [17]. The mean age of synchronous/metachronous EC/CRC in our study was 56.8 years. On analyzing the subset of women with synchronous EC/CRC, we found that they were older than those who presented with EC or CRC. This age effect may be due to the presence of mutations in the MMR genes [18, 19], although this hypothesis needs to be further investigated [10, 12, 20, 21].

Our observation that women with synchronous/metachronous EC/CRC were more commonly characterized by the onset of EC is in line with the findings from Lu et al. [22]. On analyzing 117 women with dual primary colorectal/gynecologic malignancies, the authors found that half of the gynecologic malignancies preceded the development of CRC - thereby acting as a "sentinel cancer" [22]. They also reported that the time interval between the diagnosis of $\mathrm{EC}$ and that of subsequent CRC was 11 years. In the present study, the cumulative rate for the development of CRC was within the first three years of the diagnosis of EC. In addition, the 5-year risk of developing a metachronous CRC in women diagnosed with EC was $11.9 \%$. Collectively, our data indicate that women diagnosed with EC should undergo CRC surveillance for at least five years $[23,24]$. This is particularly the case for women who present with early-stage EC.

In our study, the 5-year OS rates of women with synchronous/metachronous EC/CRC were less favorable than those observed in EC. Furthermore, a 5-year OS rate as low as 37.0\% was evident in presence of synchronous EC/CRC. These data indicate that synchronous $\mathrm{EC} / \mathrm{CRC}$ is a prognostically adverse phenotype compared to metachronous EC/CRC. Whether this is a result of specific molecular alterations needs to be addressed in genetic epidemiology studies.

There are limitations to this study. First, the TCR has no data concerning the family history of malignancies. In addition, no genetic testing was conducted on the study participants. Hence, we are unable to determine the frequency of the LS. Second, the question as to whether our results are generalizable outside Taiwan remains unanswered. Finally, it would have been interesting to include environmental and clinical risk factors in the survival analysis. Unfortunately, we had no data concerning these parameters; therefore, they could not be included in the survival model.

\section{Conclusions}


EC is the most common first tumor in Taiwanese women with metachronous EC/CRC. The 2-year risk rates of developing a metachronous tumor of interest (CRC or EC) in women diagnosed with an initial EC and CRC are not negligible. Surveillance for CRC is recommended for all women diagnosed with EC. The clinical outcomes of synchronous EC/CRC are markedly less favorable.

\section{Abbreviations}

CRC

colorectal cancer

EC

endometrial cancer

MMR

mismatch repair

LC

Lynch syndrome

NDR

National Death Registry

TCR

Taiwan Cancer Registry

\section{Declarations}

Acknowledgements This study was financially supported by the Chang Gung Memorial Foundation (grants CMRPG3J0411/2, 3J0401/02, 3J0381/0382, 3J0391/0392, and CIRPG 3K0031). The authors are grateful to Chu-Chun Huang and Jung-Erh Yang for their excellent technical assistance, and statistical assistance provided by the Clinical Trial Center, Chang Gung Memorial Hospital, Linkou, which was founded by the Ministry of Health and Welfare of Taiwan (MOHW110-TDU-B-212-124005).

Author Contributions AC and LYY: study concept and design; AC, RCW, and ASC: literature review; WYC and LYY: data analysis; AC, RCW, $\mathrm{CHW}$, and LYY: manuscript writing; $\mathrm{AC}$ and $\mathrm{CHL}$ : critical revision of the manuscript for important intellectual content. All authors approved the final version.

Conflict of interest The authors declare no conflicts of interest.

Ethical approval Ethics approval was received from the Institutional Review Board of the Chang Gung Medical Foundation (approval number: 201801202B0C502).

\section{References}

1. Lortet-Tieulent J, Ferlay J, Bray F, Jemal A (2018) International Patterns and Trends in Endometrial Cancer Incidence, 1978-2013. J Natl Cancer Inst 110(4):354-361

2. Siegel RL, Miller KD, Fuchs HE, Jemal A (2021) Cancer Statistics, 2021. CA Cancer J Clin 71(1):7-33

3. (2015) Health promotion administration ministry of health and welfare Taiwan. 2012 Cancer registry annual report, Taiwan

4. (2020) Health promotion administration ministry of health and welfare Taiwan. 2018 Cancer registry annual report, Taiwan

5. WHO Classification of Tumours Editorial Board. Female genital tumours. Lyon (France): International Agency for Research on Cancer (2020) (WHO classification of tumours series). http://publications.iarc.fr/592, vol. 4, 5th edn; 2020

6. Levine DA (2013) Integrated genomic characterization of endometrial carcinoma. Nature 497(7447):67-73

7. Lynch HT, Snyder CL, Shaw TG, Heinen CD, Hitchins MP (2015) Milestones of Lynch syndrome: 1895-2015. Nat Rev Cancer 15(3):181-194

8. Dashti SG, Chau R, Ouakrim DA, Buchanan DD, Clendenning M, Young JP et al (2015) Female Hormonal Factors and the Risk of Endometrial Cancer in Lynch Syndrome. JAMA 314(1):61-71

9. Vasen HF, Watson P, Mecklin JP, Lynch HT (1999) New clinical criteria for hereditary nonpolyposis colorectal cancer (HNPCC, Lynch syndrome) proposed by the International Collaborative group on HNPCC. Gastroenterology 116(6):1453-1456

10. Umar A, Boland CR, Terdiman JP, Syngal S, de la Chapelle A, Ruschoff J et al (2004) Revised Bethesda Guidelines for hereditary nonpolyposis colorectal cancer (Lynch syndrome) and microsatellite instability. J Natl Cancer Inst 96(4):261-268 
11. Lynch HT, Lynch J (2000) Lynch syndrome: genetics, natural history, genetic counseling, and prevention. J Clin Oncol 18(21

Suppl):19S-31S

12. Anagnostopoulos A, McKay VH, Cooper I, Campbell F, Greenhalgh L, Kirwan J (2017) Identifying Lynch Syndrome in Women Presenting With Endometrial Carcinoma Under the Age of 50 Years. Int J Gynecol Cancer 27(5):931-937

13. Barrow E, Hill J, Evans DG (2013) Cancer risk in Lynch Syndrome. Fam Cancer 12(2):229-240

14. Chiang CJ, Wang YW, Lee WC (2019) Taiwan's Nationwide Cancer Registry System of 40 years: Past, present, and future. J Formos Med Assoc 118(5):856-858

15. Kavuluru R, Hands I, Durbin EB, Witt L (2013) Automatic Extraction of ICD-O-3 Primary Sites from Cancer Pathology Reports. AMIA Jt Summits Transl Sci Proc 2013:112-116

16. Lu TH, Lee MC, Chou MC (2000) Accuracy of cause-of-death coding in Taiwan: types of miscoding and effects on mortality statistics. Int J Epidemiol 29(2):336-343

17. Lee KD, Chen CY, Huang HJ, Wang TY, Teng D, Huang SH et al (2015) Increased risk of second primary malignancies following uterine cancer: a population-based study in Taiwan over a 30-year period. BMC Cancer 15:393

18. Wagner A, Hendriks Y, Meijers-Heijboer EJ, de Leeuw WJ, Morreau H, Hofstra R et al (2001) Atypical HNPCC owing to MSH6 germline mutations: analysis of a large Dutch pedigree. J Med Genet 38(5):318-322

19. Hendriks YM, Wagner A, Morreau H, Menko F, Stormorken A, Quehenberger F et al (2004) Cancer risk in hereditary nonpolyposis colorectal cancer due to MSH6 mutations: impact on counseling and surveillance. Gastroenterology 127(1):17-25

20. Buchanan DD, Tan YY, Walsh MD, Clendenning M, Metcalf AM, Ferguson K et al (2014) Tumor mismatch repair immunohistochemistry and DNA MLH1 methylation testing of patients with endometrial cancer diagnosed at age younger than 60 years optimizes triage for population-level germline mismatch repair gene mutation testing. J Clin Oncol 32(2):90-100

21. Mills AM, Liou S, Ford JM, Berek JS, Pai RK, Longacre TA (2014) Lynch syndrome screening should be considered for all patients with newly diagnosed endometrial cancer. Am J Surg Pathol 38(11):1501-1509

22. Lu KH, Dinh M, Kohlmann W, Watson P, Green J, Syngal S et al (2005) Gynecologic cancer as a "sentinel cancer" for women with hereditary nonpolyposis colorectal cancer syndrome. Obstet Gynecol 105(3):569-574

23. Win AK, Lindor NM, Winship I, Tucker KM, Buchanan DD, Young JP et al (2013) Risks of colorectal and other cancers after endometrial cancer for women with Lynch syndrome. J Natl Cancer Inst 105(4):274-279

24. Aarnio M, Sankila R, Pukkala E, Salovaara R, Aaltonen LA, de la Chapelle A et al (1999) Cancer risk in mutation carriers of DNAmismatch-repair genes. Int J Cancer 81(2):214-218

\section{Figures}




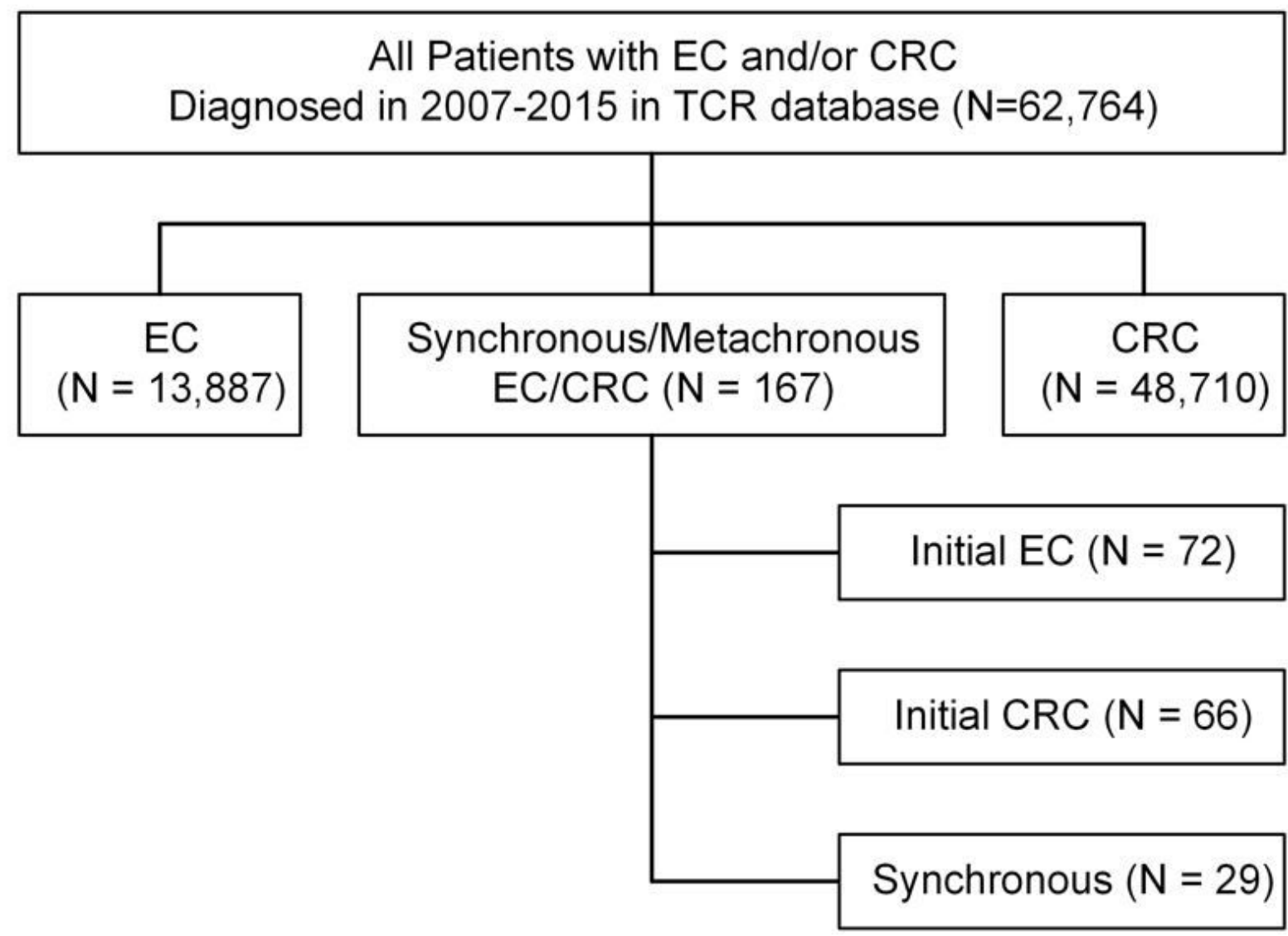

Figure 1

Figure 1

Flow diagram of the study. Abbreviations: EC, endometrial cancer; CRC, colorectal cancer. 


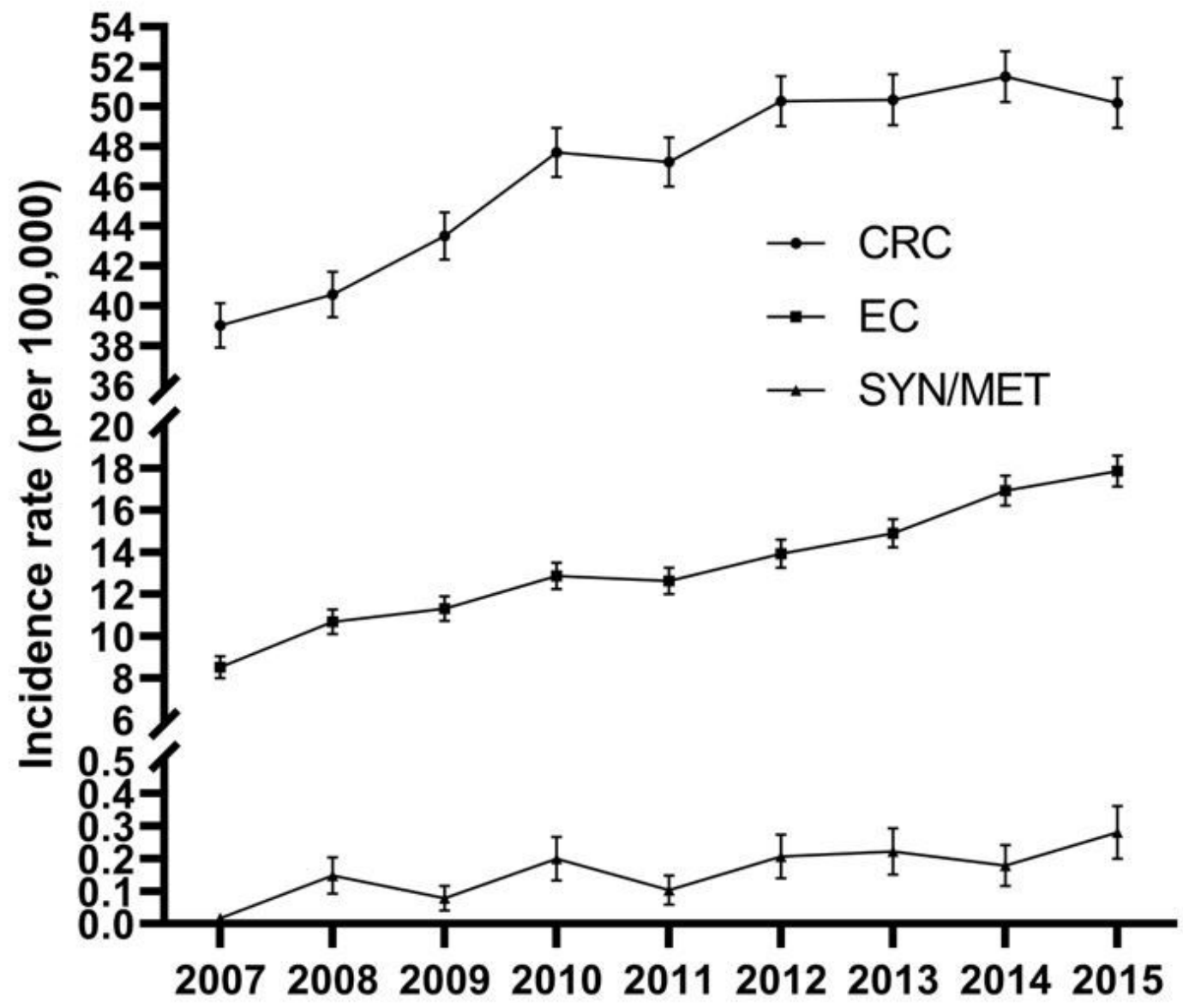

Figure 2

\section{Figure 2}

Trends for the incidence of EC, CRC, and synchronous/metachronous EC/CRC in Taiwanese women. Abbreviations: SYN/MET: synchronous/metachronous. 


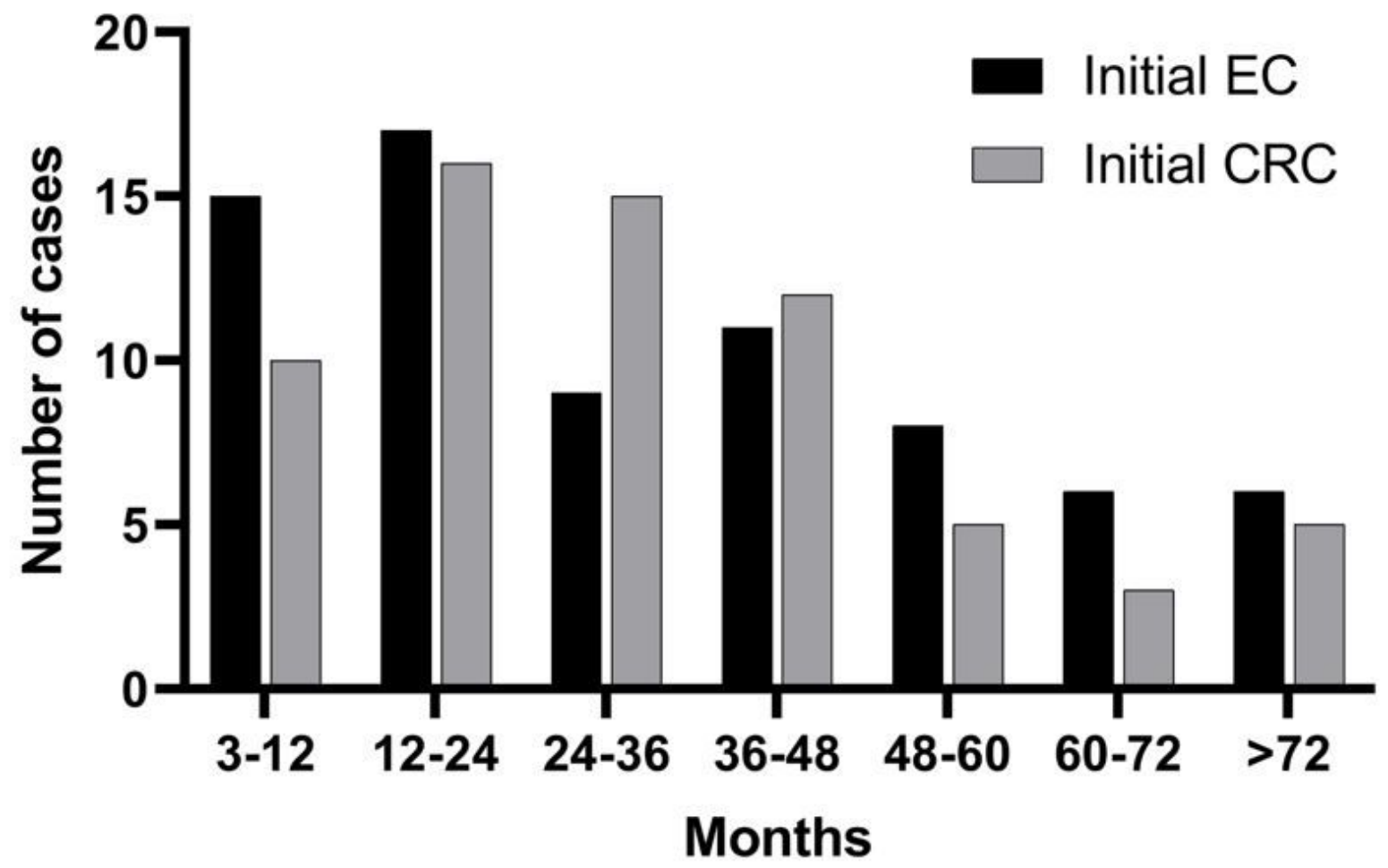

Figure 3

Figure 3

Number of cases with metachronous EC/CRC according to different time frames from the first cancer diagnosis. 


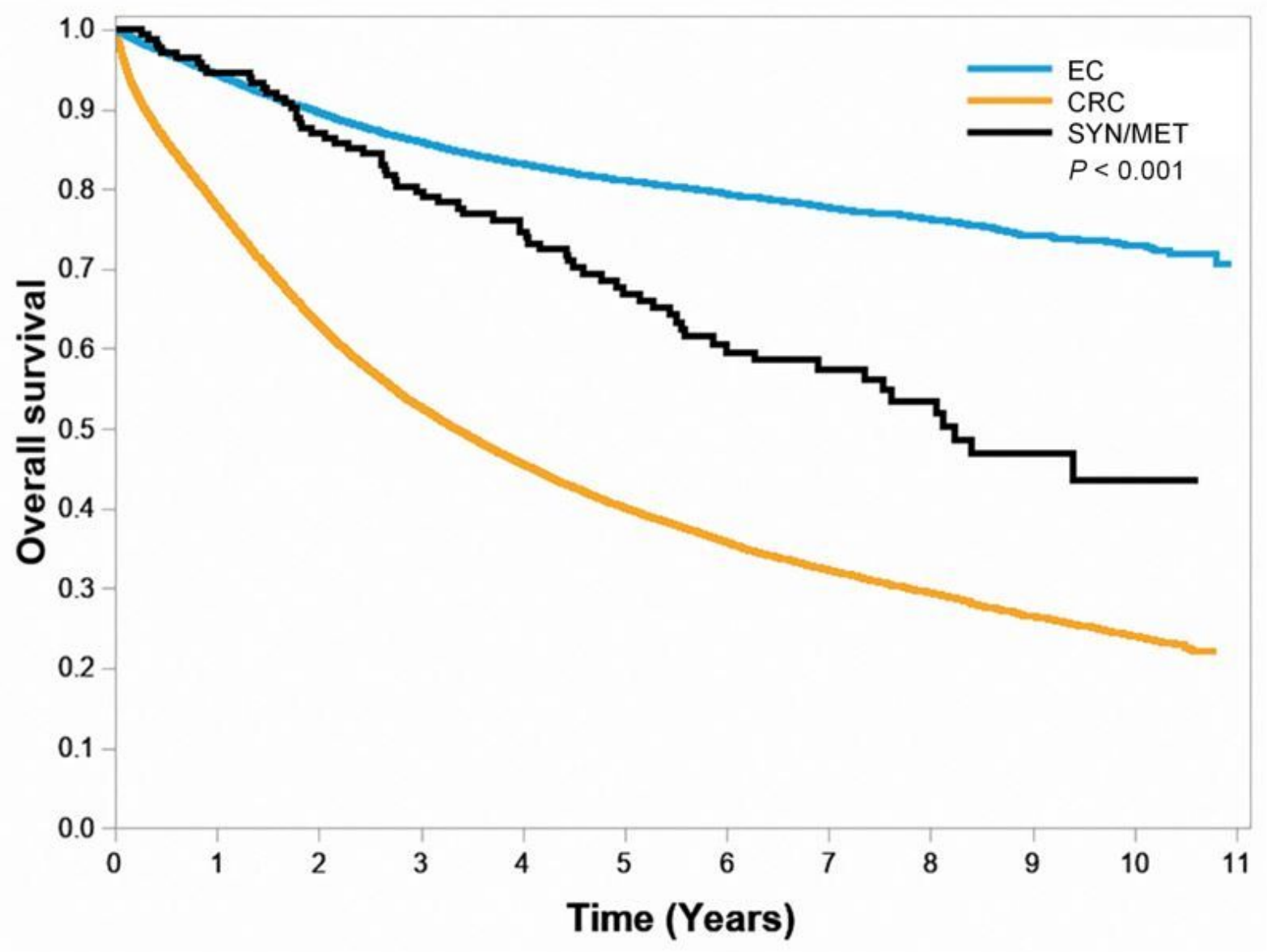

Figure 4

Figure 4

Overall survival figures of women with EC, $\mathrm{CRC}$, and synchronous/metachronous EC/CRC. Abbreviations: EC, endometrial cancer; $C R C$, colorectal cancer. Abbreviations: SYN/MET: synchronous/metachronous. 


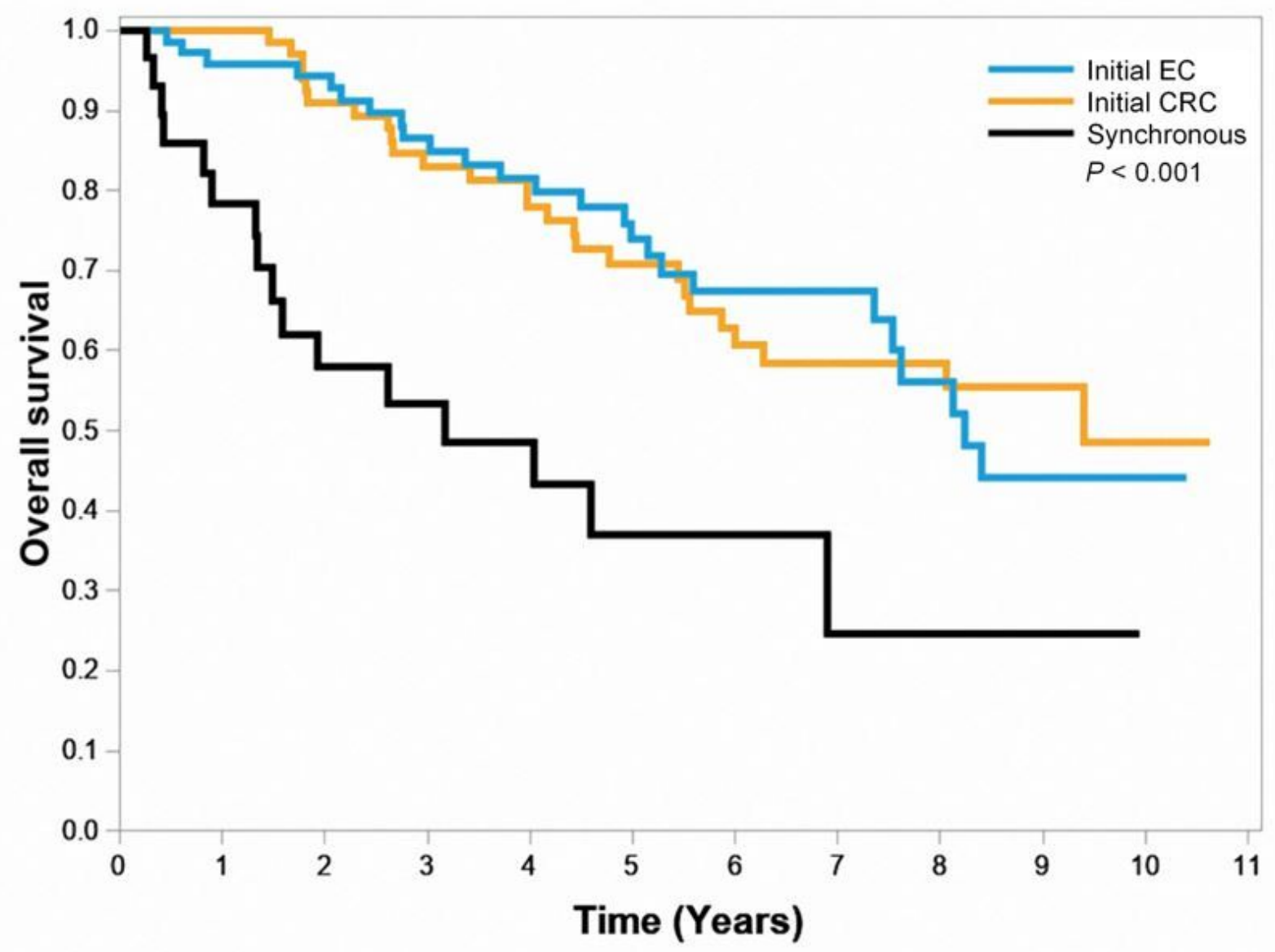

Figure 5

Figure 5

Overall survival figures of women with synchronous EC/CRC versus metachronous EC/CRC according to the chronological presentation of tumors. 